\title{
Hypoplastic optic nerves and pituitary dysfunction
}

\author{
A spectrum of anatomical and endocrine abnormalities
}

\author{
R STANHOPE, M A PREECE, AND C G D BROOK \\ Department of Paediatrics, The Middlesex Hospital and The Institute of Child Health, Guilford Street, \\ London
}

SUMMARY Fourteen children with optic nerve hypoplasia associated with either mid-brain abnormalities or pituitary dysfunction, or both, are described. All patients were either partially sighted or blind. One case is reported in detail. The importance of hypoglycaemia in the neonatal period and later in childhood is emphasised in relation to diagnosis and developmental delay. Pituitary dysfunction is variable and may be progressive. Forty percent of the patients had a septum pellucidum and its presence or absence cannot be used as a radiological marker for the condition. Long term endocrine follow up of these patients is required.

Congenital optic nerve hypoplasia is now more frequently recognised. ${ }^{1}$ The association of optic nerve hypoplasia and absence of the septum pellucidum was first described in $1941 .^{2}$ In 1956 in a post mortem study, 36 cases of absence of the septum pellucidum, 9 of which had optic nerve hypoplasia, were described. ${ }^{3}$ The syndrome of septo-optic dysplasia, the name given by de Morsier to the association, implies an absent septum pellucidum. The endocrinopathy associated with septo-optic dysplasia in childhood has since been documented. 45

have been described with a normal septum pellucidum. ${ }^{6-9}$ The diagnosis may only become apparent in adult life, ${ }^{10-12}$ but missing the diagnosis in childhood may have serious consequences because growth hormone deficiency and hypoglycaemia are not uncommon. ${ }^{13}{ }^{14}$ This series is reported to draw attention to the features that should alert physicians to begin early treatment.

\section{Patients}

Case report (case 5). A girl weighing $3 \mathrm{~kg}$ was born by normal delivery after an unremarkable pregnancy. She had hypoglycaemia during the first days of life. At 2 months of age blindness was noticed and bilateral optic atrophy was diagnosed. Her developmental milestones were more delayed than would have been accounted for by her partial vision. Convulsions, occurring in the early morning before breakfast, started at the age of 8 years but treatment with sodium valproate did not reduce the seizure rate. Blood sugar was not measured during any seizure. Computed tomography (CT) showed a normal septum pellucidum.

At the age of 6 years her height was well below the third centile (Figure). Despite a low height velocity, no endocrine assessment was undertaken because a CT scan showed the presence of the septum pellucidum. At 14 years of age she was referred for assessment at the Middlesex Hospital. A high resolution CT scan showed hypoplastic optic nerves and chiasma; the pituitary gland and sella tureica were small. After intravenous insulin $(0 \cdot 15$ $\mathrm{U} / \mathrm{kg}$ ) she had profound hypoglycaemia with inadequate cortisol and growth hormone responses. Although endocrine replacement treatment has now begun, the probable damage from her hypoglycaemia is irreversible and unfortunately, as she has signs of early puberty, her ultimate height will be very short.

This case with its unfortunate sequelae prompted a review of our experience of 14 patients with optic nerve hypoplasia and pituitary dysfunction. All patients had typical fundal changes of optic nerve hypoplasia, either unilateral or bilateral, as previously described. ${ }^{5}{ }^{15}$ In addition they had an absent septum pellucidum or pituitary dysfunction, or both. The neurological and endocrinological data of the 14 patients are summarised in the Table. Patients 1 to 4 have been reported previously. ${ }^{5}$ 
Figure Growth chart and photograph of patient in case 5. The solid square represents bone age. Maternal (M) and paternal $(F)$ centiles are shown on the right hand border. 


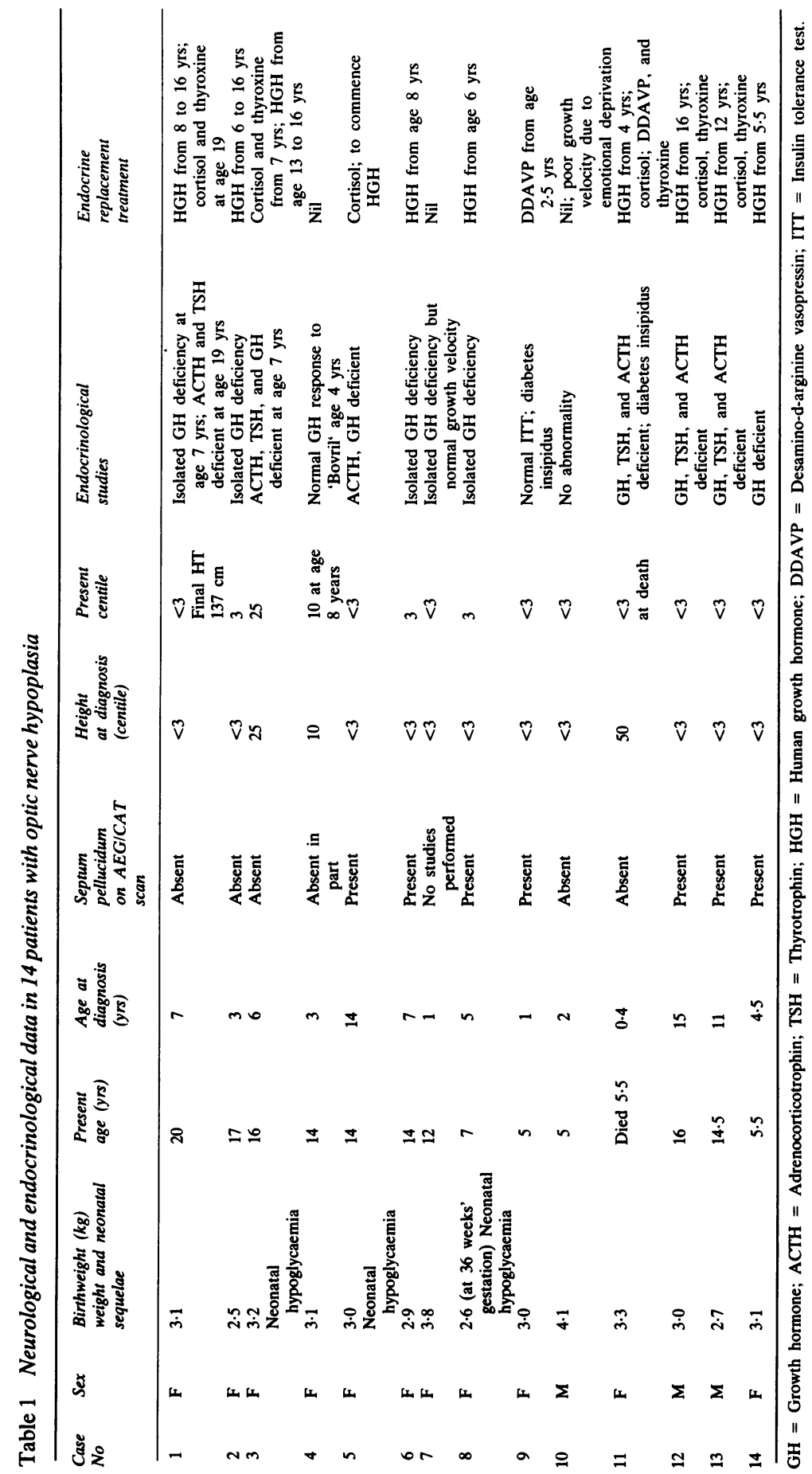




\section{Results}

Eleven of the 14 patients were girls. Although blindness was always noticed in the first year of life, the average age at diagnosis was 5.4 years. In case 5, however, and despite neonatal symptoms the diagnosis was not made until age 14 years. Three patients had neonatal hypoglycaemic convulsions which recurred in later childhood. In none of these children did the hypoglycaemia point to an early diagnosis.

Of the 13 patients who had had neuroradiological studies, 7 had a normal septum pellucidum and in one additional patient the septum pellucidum was present in part. Eleven patients were below the 3rd centile for height at presentation. Only one was above the 25th centile, either at presentation or after treatment. Varying hypothalamo-pituitary dysfunction was found, from isolated defects to panhypopituitarism. Two patients (cases 1 and 11) had a progressive endocrine deficiency.

\section{Discussion}

The endocrine and anatomical associations of optic nerve hypoplasia have been described for more than a decade $4-6$ but we have seen four children recently (cases 5, 8, 12, and 14) in whom the diagnosis had been delayed unnecessarily. In cases 5,9 , and 12 , the presence of the septum pellucidum was believed to exclude the endocrinopathy. This series has confirmed previous reports $^{6-9}$ that the septum pellucidum is frequently present in 'septo-optic' dysplasia and the presence or absence of septum pellucidum gives no indication of the possible endocrine dysfunction. In two patients (cases 5 and 13) the characteristic appearance of optic nerve hypoplasia was mistaken for optic atrophy.

Although the mid brain lesion and visual impairment are present from birth, the endocrine abnormalities may evolve later in life. The retarded developmental progress that is characteristic of these children may be partly due to recurrent hypoglycaemia and partly to visual impairment. Late diagnosis may allow irreversible neuronal damage from hypoglycaemia as well as a reduction in final height. Pituitary dysfunction may present as neonatal hypoglycaemia and this should provide an additional clue to early diagnosis and treatment. No treatment is available to alleviate the visual defects, but recurrent hypoglycaemia and short stature are unnecessary additional handicaps.

We recommend that in patients with congenital blindness because of optic nerve hypoplasia, endocrine assessment should be mandatory, irrespective of the presence or absence of mid-brain lesions on neuroradiology. All such patients should be followed for life. An increased awareness of the association of hypoplastic optic nerves and pituitary dysfunction is required by both ophthalmologists and paediatricians if late diagnosis is to be avoided.

\section{References}

${ }^{1}$ Edwards WC, Layden WE. Optic nerve hypoplasia. Am J Ophthalmol 1970;70:950-9.

2 Reeves DL. Congenital absence of the septum pellucidum. Bulletin of the Johns Hopkins Hospital 1941;69:61-71.

3 de Morsier G. Études sur les dysraphies crânio-encéphaliques. III. Agénésie du septum lucidum avec malformation du tractus optique. La dysplasie septo-optique. Schweiz Arch Neurol Neurochir Psychiatr 1956;77:267-92.

4 Hoyt WF, Kaplan SL, Grumbach MM, Glaser TS. Septo-optic dysplasia and pituitary dwarfism (letter). Lancet 1970;i:893-4.

5 Brook CGD, Sanders MD, Hoare RD. Septo-optic dysplasia. Br Med J 1972;iii:811-3.

${ }^{6}$ Kaplan SL, Grumbach MM, Hoyt WF. A syndrome of hypopituitary dwarfism, hypoplasia of optic nerves and malformation of the prosencephalon: report of 6 patients (abstract). Pediatr Res 1970;4:480-1.

${ }^{7}$ Billson F, Hopkins IJ. Optic hypoplasia and hypopituitarism (letter). Lancet 1972;i:905.

8 Patel H, Tze WJ, Crichton JU, McCormick AQ, Robinson GC, Dolman CL. Optic nerve hypoplasia with hypopituitarism. Am J Dis Child 1975;129:175-80.

9 Huseman CA, Kelch RP, Hopwood NJ, Zipf WB. Sexual precocity in association with septo-optic dysplasia and hypothalmic hypopituitarism. J Pediatr 1978;92:748-53.

10 Ellenberger C, Jr, Runyan TE. Holoprosencephaly with hypoplasia of optic nerves, dwarfism and angenesis of the septum pellucidum. Am J Ophthalmol 1970;70:960-7.

11 Wilson PW, Easley RB, Bolander FF, Hammond CB. Evidence for a hypothalmic defect in septo-optic dysplasia. Arch Intern Med 1978;138:1276-7.

12 Rush JA, Bajandas FJ. Septo-optic dysplasia (de Morsier syndrome). Am J Ophthalmol 1978;86:202-5.

13 Harris RJ, Haas L. Septo-optic dysplasia with growth hormone deficiency. (de Morsier syndrome). Arch Dis Child 1972;47: 973-6.

14 Frisch H, Schober E. Opticushypoplasie und Wachstumshormon-Mangel de Morsier Syndrome. Monatsschr Kinderbeilkd 1980:128:50-2.

15 Sanders MD, Brook CGD. Septo-optic dysplasia. Trans Ophthalmol Soc UK 1974;94:197-202.

Correspondence to Dr C G D Brook, The Middlesex Hospital, Mortimer Street, London W1N 8AA.

Received 31 October 1983

\section{Addendum}

In December 1983 a boy aged 11 weeks was referred to this hospital with intractable hypoglycaemia and a predominantly conjugated hyperbilirubinaemia. Fundoscopy showed hypoplasia of the right optic disc and high resolution computed tomography showed unilateral optic nerve and pituitary hypoplasia with an intact septum pellucidum. The baby has growth hormone, adrenocorticotrophic hormone, and thyroid stimulating hormone deficiencies. 